EXTENDED REPORT

\title{
Autoimmune thyroiditis and anti-thyroid antibodies in primary Siögren's syndrome: a case-control study
}

\author{
R Tunc, M S Gonen, O Acbay, V Hamuryudan, H Yazici
}

Ann Rheum Dis 2004;63:575-577. doi: 10.1136/ard.2003.010058

See end of article for authors' affiliations

......................

Correspondence to:

Dr Recep Tunc, Selcuk

Universitesi, Meram Tip

Fakultesi, lc Hastalıkları

$\mathrm{ABD}$, Romatoloji $\mathrm{BD}$,

Konya, Turkey; trecep@

hotmail.com

Accepted 22 July 2003

Objective: To determine the frequency of antithyroid antibodies and the presence of autoimmune thyroiditis among patients with primary Siögren's syndrome.

Design: A case-control study.

Methods: 53 consecutive patients with primary Sjögren's syndrome, 30 with rheumatoid arthritis, 12 with secondary Siögren's syndrome associated with rheumatoid arthritis, 17 with autoimmune thyroiditis, and 53 apparently healthy controls were studied for anti-TG and anti-TPO antibodies as well as serum thyroid hormones and TSH levels.

Results: The overall frequencies of thyroid antibodies were 6/53 (1 1\%) in primary Siögren's syndrome, 2/ $30(7 \%)$ in rheumatoid arthritis, $2 / 12(17 \%)$ in secondary Siögren's syndrome, 4/53 (8\%) in healthy controls, and $16 / 17(94 \%)$ in autoimmune thyroiditis. There was no difference in the frequency of the thyroid antibodies among the groups if patients with autoimmune thyroiditis were excluded $(p=0.415$ for anti-TPO; $p=0.275$ for anti-TG; $p=0.696$ for either anti-TG and/or anti-TPO). Only two patients with primary Sjogren's syndrome had clinical hypothyroidism associated with autoimmune thyroiditis.

Conclusions: In this Turkish population, no association between primary Sjögren's syndrome and autoimmune thyroiditis was found.

C hronic autoimmune thyroiditis is an organ specific autoimmune disorder characterised by disturbed thyroid function and organ specific autoantibodies against to thyroglobulin (anti-TG) and thyroid peroxidase (antiTPO). Sjögren's syndrome, on the other hand, is a non-organspecific systemic autoimmune disease with diverse clinical manifestations such as Raynaud's phenomenon, arthritis, and vasculitis.

An association between primary Sjögren's syndrome with autoimmune thyroiditis has been reported. ${ }^{1-8}$ However, controlled studies looking at this association have been few and the results have not been uniform. ${ }^{910}$ We therefore addressed this issue in a case-control protocol.

\section{METHODS \\ Patients}

We studied 53 consecutive patients with primary Sjögren's syndrome, 30 patients with rheumatoid arthritis, and 12 patients with secondary Sjögren's syndrome associated with rheumatoid arthritis in the rheumatology outpatients clinic at the Cerrahpasa Medical Faculty in Istanbul, Turkey.

We also recruited as positive and negative controls 17 patients with autoimmune thyroiditis currently attending the endocrinology outpatients clinic of the same institution and 53 healthy controls from among hospital staff and their relatives, age and sex matched for the patients with primary Sjögren's syndrome. None of the healthy controls had sicca symptoms or were receiving drugs that might affect thyroid function. The patients and controls were advised about the investigational nature of the study. None refused to participate.

The patients with primary Sjögren's syndrome all had definite disease according to the European criteria. ${ }^{11}$ All patients had the clinical symptoms of dry eyes and mouth, a positive Schirmer's test (less than $5 \mathrm{~mm}$ wetting of a strip of filter paper per five minutes), and Rose Bengal staining (increased uptake of Rose Bengal dye in devitalised areas in the conjunctiva and cornea) along with the presence of at least one of the following autoantibodies: anti-Ro, anti-La, antinuclear antibodies (ANA), rheumatoid factor (RF). All patients had clinically dry mouth, but formal salivary flow studies were not done. Their diagnoses had all been confirmed by lip biopsies showing clusters of at least 50 lymphocytes (foci). All primary Sjögren's syndrome patients reported here had at least a foci score of $1,{ }^{12}$ and only patients with primary Sjögren's syndrome had lip biopsies.

Eight of the 53 patients with primary Sjögren's syndrome (15\%) had arthritis; among these four had a symmetrical arthritis. None, however, had erosions. The frequencies for positivity for ANA, RF, anti-Ro, and anti-La were 43/50 (86\%), 33/47(70\%), 28/44 (63\%), and 25/44 (57\%), respectively.

The control patients with a diagnosis of rheumatoid arthritis or secondary Sjögren's syndrome were classified according to the revised criteria of the American College of Rheumatology (ACR) ${ }^{13}$ and the European criteria, ${ }^{11}$ respectively.

\section{Antithyroid antibodies}

Anti-thyroglobulin (anti-TG) and anti-thyroid peroxidase (anti-TPO) antibodies were measured using Immulite antiTG and TPO kits (Euro/DPC, UK). These kits use the chemiluminescent immunometric assay method with the respective normal ranges of 0 to 40 and 0 to $60 \mathrm{IU} / \mathrm{ml}$.

\section{Thyroid hormones and TSH}

The T3 and T4 levels were measured using Ciba Corning Diagnostics Corporation kits (Madfield, Massachusetts, USA) employing a competitive immunoassay method, with normal

Abbreviations: ACR, American College of Rheumatology; ANA, antinuclear antibodies; anti-TG and anti-TPO, autoantibodies against thyroglobulin and thyroid peroxidase; RF, rheumatoid factor; TSH, thyroid stimulating hormone 
ranges of 82 to $179 \mathrm{ng} / \mathrm{dl}$ and 4.5 to $12.5 \mathrm{mg} / \mathrm{dl}$, respectively. TSH levels were also measured using a Ciba Corning kit, employing a two site chemiluminometric immunoassay method, with a normal range of 0.4 to $4.0 \mathrm{mIU} / \mathrm{ml}$.

\section{Statistical analysis}

Age, thyroid hormones, and THS levels among the groups were analysed by one way analysis of variance (ANOVA). Pearson's $\chi^{2}$ test was used to compare the sex distribution and antithyroid antibody positivity among the groups.

\section{RESULTS}

Demographic characteristics are summarised in table 1. The patients with autoimmune thyroiditis were about a decade younger $(F=2.412, p=0.051)$ than the rest of the group, while the sex distribution was similar in all groups $(\mathrm{p}=0.889)$.

The distribution of antithyroid antibodies in all groups is also shown in table 1. The frequencies of anti-TPO and antiTG were, as expected, significantly increased (both $\mathrm{p}<0.001$ ) among the patients with autoimmune thyroiditis, while again, as expected, all patients but one with autoimmune thyroiditis tested positive for one or other thyroid autoantibody at the time of the study $(\mathrm{p}<0.001)$. Excluding the patients with autoimmune thyroiditis, the levels of the same antibodies were not significantly different among the remaining two groups of patients and the healthy controls $(\mathrm{p}=0.415$ for anti-TPO; $\mathrm{p}=0.275$ for anti-TG; $\mathrm{p}=0.696$ for either anti-TG and/or anti-TPO).

Two (4\%) of the patients with primary Sjögren's syndrome were identified as having clinically definite autoimmune thyroiditis during our survey. One was being followed at the endocrinology outpatient clinic and was receiving thyroid replacement therapy. The second patient was diagnosed for the first time during this study as having autoimmune thyroiditis. She had an enlarged thyroid gland with hypothyroidism. She also had antithyroid antibodies and abnormal thyroid hormone levels. One further patient had slightly raised TSH $(7.74 \mathrm{mIU} / \mathrm{ml}$; normal $=0.4$ to $4.0 \mathrm{mIU} /$ $\mathrm{ml}$ ) with no clinical hypothyroidism or antithyroid antibodies. Fine needle aspiration biopsy of the thyroid of this patient showed a mononuclear cell infiltration. She was diagnosed as having a seronegative autoimmune thyroiditis. All other patients and controls with or without thyroid antibodies had normal TSH and thyroid hormones.

The medical histories and thyroid gland examinations of other patients with thyroid antibodies but normal TSH and thyroid hormone levels were all normal or negative for thyroid disease.

Finally, if the patients with autoimmune thyroiditis were excluded there were no statistically significant differences in serum T3, T4, and TSH levels among the study groups $(\mathrm{F}=0.163, \mathrm{p}=0.84$ for serum $\mathrm{T} 3 ; \mathrm{F}=1.512, \mathrm{p}=0.21$ for serum T4; and $\mathrm{F}=0.152, \mathrm{p}=0.85$ for serum TSH) (table 2 ).
Table 2 Mean serum T3, T4, and TSH among the groups

\begin{tabular}{lllll}
\hline Groups & $\mathbf{n}$ & T3 $(\mathbf{n g} / \mathbf{m l})$ & T4 $(\mathbf{m g} / \mathbf{d l})$ & TSH $(\mathbf{m l U} / \mathbf{m l})$ \\
\hline PSS & 53 & $130(24)$ & $9.7(2.5)$ & $1.48(1.14)$ \\
RA & 30 & $130(38)$ & $9.8(1.8)$ & $1.61(1.10)$ \\
SSS & 12 & $136(28)$ & $10.1(2.3)$ & $1.48(1.14)$ \\
Healthy & 53 & $135(22)$ & $9.4(1.7)$ & $1.56(0.68)$
\end{tabular}

Values are mean (SD).

F, female; M, male; PSS, primary Sïgren's syndrome; RA, rheumatoid arthritis; SSS, secondary Sjögren's syndrome, TSH, thyroid stimulating hormone; T3, tri-iodothyronine; T4, thyroxine.

\section{DISCUSSION}

In this study, we found that the frequency of thyroid antibodies was $11 \%$ among the patients with primary Sjögren's syndrome. This was not different than that observed among our healthy controls ( $8 \%$ ).

In a family study of primary Sjögren's syndrome, Foster et al reported that index cases and first degree relatives of patients with primary Sjögren's syndrome had more frequent thyroid disease $(p<0.001)$ and thyroid antibodies $(p<0.001$ both for anti-TPO and anti-TG) when compared with historical controls. ${ }^{6}$ In support of this, Punzi et al reported an increase in the frequency of anti-TPO (17.6\% $v 9 \%$; $\mathrm{p}<0.05)$ and anti-TG $(13.4 \% \vee 1 \% ; \mathrm{p}<0.001)$ in 119 female patients with primary Sjögren's syndrome compared with 199 female controls. ' In contrast, Ramos-Casals et al reported 32 cases of autoimmune thyroiditis among 160 patients with primary Sjögren's syndrome $(20 \%)$, a frequency not different than that observed among their controls $(17 \% ; p=0.628)$ who were age and sex matched subjects from a primary care centre with no symptoms of Sjögren's syndrome and who had not received drugs that might have altered thyroid function. ${ }^{10}$ Finally, Petri at al, looking at the reverse association, reported that there was no increase in the frequency of rheumatological symptoms, including dry eyes and mouth, and systemic autoantibodies, except ANA but including anti-Ro and anti-La, in patients with autoimmune thyroiditis compared with patients with thyroid disease other than autoimmune thyroiditis. ${ }^{14}$

The cross sectional design and the fact that the patients were not stratified according to disease activity can be considered limitations of our study. In future studies the effects of the course and activity of the disease on the frequency and the titre of the antithyroid antibodies should also be explored.

Another potential drawback of our study was the rather limited number of patients with secondary Sjögren's syndrome and autoimmune thyroiditis who could be studied. This also needs to be taken into account in future studies. Notwithstanding the importance of sample size, however, there were no clear cut trends in the frequency of the antibodies we were studying, and this gives us confidence in our data.

Table 1 Age and sex distribution and frequency of antithyroid antibodies among the groups

\begin{tabular}{llllllll}
\hline Group & $\mathbf{n}$ & $\mathbf{F} / \mathbf{M}$ & Age (years) & Anti-TPO $(\%)$ & Anti-TG $(\%)$ & Both (\%) & Total $(\%)$ \\
\hline PSS & 53 & $51 / 2$ & $51.8(14.8)$ & $5(9)$ & $5(9)$ & $4(8)$ & $6(11)$ \\
RA & 30 & $28 / 2$ & $51.1(12.2)$ & $2(7)$ & $0(0)$ & $0(0)$ & $2(7)$ \\
SSS & 12 & $12 / 0$ & $57.3(11.6)$ & $2(17)$ & $1(8)$ & $1(8)$ & $2(17)$ \\
Healthy & 53 & $51 / 2$ & $52.0(15.4)$ & $2(4)$ & $2(4)$ & $0(0)$ & $4(8)$ \\
AlT & 17 & $16 / 1$ & $41.8(15.8)$ & $14(83)$ & $6(35)$ & $4(24)$ & $16(94)$ \\
\hline
\end{tabular}

Values are $\mathrm{n}(\%)$ or, for age, mean (SD).

Anti-TG, autoantibodies against thyroglobulin; anti-TPO, autoantibodies against thyroid peroxidase; AIT, autoimmune thyroiditis; F, female; M, male; PSS, primary Sjögren's syndrome; RA, rheumatoid arthritis; SSS, secondary Siögren's syndrome. 
Table 3 Frequency of antithyroid antibodies and autoimmune thyroiditis in association with primary Sjögren's syndrome: summary of previous publications and a comparison of their results with our findings

\begin{tabular}{|c|c|c|c|c|c|c|c|}
\hline Country & $\mathbf{n}$ & TPO (\%) & TG (\%) & Both (\%) & Total (\%) & AIT (\%) & Criteria \\
\hline USA $^{1}$ & 24 & $10(42)^{\star *}$ & $5(21)$ & $5(21)$ & $10(42)^{* *}$ & $13(54)^{* *}$ & NA \\
\hline Italy ${ }^{2}$ & 8 & NA & NA & NA & $6(75)^{* *}$ & $2(25)^{*}$ & NA \\
\hline $\mathrm{UK}^{3}$ & 100 & $40(40)^{* *}$ & NA & NA & $40(40)^{\star *}$ & $14(14)$ & Fox's criteria \\
\hline France $^{4}$ & 26 & NA & $26(100)^{\star *}$ & NA & $26(100)^{* *}$ & $8(31)^{* *}$ & Fox's criteria \\
\hline Sweden ${ }^{5}$ & 28 & $10(36)^{* *}$ & $10(36)^{* *}$ & $10(36)^{* *}$ & $10(36)^{* *}$ & $5(18)^{*}$ & Copenhagen $^{18}$ \\
\hline $\mathrm{UK}^{6}+$ & 42 & $14(33)^{* *}$ & $6(14)$ & NA & NA & NA & Fox's criteria \\
\hline Mexico ${ }^{7}$ & 33 & $15(45)^{\star *}$ & $6(18)$ & NA & $16(48)^{* *}$ & $11(33)^{*}$ & NA \\
\hline $\mathrm{UK}^{8}$ & 74 & $17(23)^{*}$ & NA & NA & NA & NA & Fox's criteria \\
\hline Italy ${ }^{9} t$ & 119 & $21(18)$ & $16(13)$ & NA & 22 (19) & $16(13)$ & ECSG \\
\hline $\operatorname{Spain}^{10} \dagger$ & 160 & 25 (16) & 20 (13) & NA & NA & $32(20)^{* *}$ & ECSG \\
\hline Turkey (CS)† & 53 & $5(9)$ & $5(9)$ & $4(8)$ & $6(11)$ & $2(4)$ & ECSG \\
\hline
\end{tabular}

${ }^{*} \mathrm{p}<0.05,{ }^{* *} \mathrm{p}<0.01$ : results of current study $v$ those of previous studies.

†Controlled studies.

AIT, autoimmune thyroiditis; CS, current study; ECSG, European Community Study Group; NA, not available; TG, thyroglobulin; TPO, thyroid peroxidase.

An interesting finding of our study was the observation that the frequency of antithyroid antibodies among our patients with primary Sjögren's syndrome tended to be lower than that reported from other countries (table 3). It is known that some autoimmune diseases show geographical differences. The prevalence of pericardial disease is low in Turkish patients with rheumatoid arthritis, ${ }^{15}$ and systemic lupus erythematosus is more common in certain Asian populations and may be more severe among hispanics and native Americans than among whites in the United States. ${ }^{16}$ Moreover the frequency of certain antibodies, such as anti$\mathrm{Sm}$, also differs in patients with systemic lupus erythematosus reported from different geographical regions. ${ }^{17}$ Our finding of a lower frequency of autoantibodies among our patients with primary Sjögren's syndrome may indicate yet another geographical difference in autoantibody production, the reasons for which need to be elucidated. We remain cautious in our conclusions, in that a proper assessment of these differences would require matched comparisons of demography, disease severity, and disease duration, which were not available in the present study.

In conclusion, in a case-control study we have not been able to show an association between primary Sjögren's syndrome and autoimmune thyroiditis in a Turkish population.

\section{Authors' affiliations}

R Tunc, Department of Internal Medicine, Division of Rheumatology, Meram School of Medicine, Selcuk University, Konya, Turkey

M S Gonen, Department of Internal Medicine, Division of Endocrinology, Meram School of Medicine

O Acbay, Department of Internal Medicine, Division of Endocrinology, Cerrahpasa School of Medicine, Istanbul University, Istanbul, Turkey V Hamuryudan, H Yazici, Department of Internal Medicine, Division of Rheumatology, Cerrahpasa School of Medicine

\section{REFERENCES}

1 Karsh J, Pavlidis N, Weintraub BD, Mautsopoulos HM. Thyroid disease in Siögren's syndrome. Arthritis Rheum 1980;23:1326-9.
2 Loviselli A, Mathieu A, Pala R, Mariotti S, Cau S, Marongiu C, et al. Development of thyroid disease in patients with primary and secondary Sjögren's syndrome. J Endocrinol lnvest 1988;1 1:653-6.

3 Kelly CA, Foster H, Pal B, et al. Primary Sjögren's syndrome in north east England: a longitudinal study. Br J Rheumatol 1991;30:437-42

4 Bouanani M, Bataille R, Piechaczyk M, Salhi SL, Pau B, Bastide M. Autoimmunity to human thyroglobulin. Respective epitopic specificity patterns of anti-human thyroglobulin autoantibodies in patients with Sjögren's syndrome and patients with Hashimoto's thyroiditis. Arthritis Rheum 1991;34:1585-93.

5 Hansen BU, Ericsson UB, Henricsson V, Larsson A, Manthorpe R, Warfvinge $G$. Autoimmune thyroiditis and primary Sjögren's syndrome: clinical and laboratory evidence of the coexistence of the two diseases. Clin Exp Rheumatol 1991;9:137-41.

6 Foster H, Fay A, Kelly C, et al. Thyroid disease and other autoimmune phenomenon in a family study of primary Sjögren's syndrome. Br J Rheumatol 1993:32:36-40.

7 Perez EB, Kraus A, Lopez G, et al. Autoimmune thyroid disease in primary Siögren's syndrome. Am J Med 1995;99:480-4.

8 Davidson BKS, Kelly CA, Griffiths ID. Primary Sjögren's syndrome in north east of England: a long-term follow-up study. Rheumatology 1999:38:245-53.

9 Punzi L, Ostuni PA, Betterle C, et al. Thyroid gland disorders in primary Siögren's syndrome. Rev Rhum Engl Ed 1996;63:809-14.

10 Ramos-Casals M, Garcia-Carrasco M, Cervera R, et al. Thyroid disease in primary Siögren's syndrome study in a series of 160 patients. Medicine (Baltimore) 2000;79:103-8.

11 Vitali C, Bombardieri S, Moutsopoulos HM, et al. Preliminary criteria for the classification of Siögren's syndrome. Results of a prospective concerted action supported by the European Community. Arthritis Rheum 1993;36:340-7.

12 Workshop on Diagnostic Criteria for Siögren's syndrome I. Questionnaires for dry eye and dry mouth. II. Manual of methods and procedures. Clin Exp Rheumatol 1989:7:212-19.

13 Arnett FC, Edworthy SM, Bloch DA, McShane DJ, Fries JF, Cooper NS, et al. The American Rheumatism Association 1987 revised criteria for the classification of rheumatoid arthritis. Arthritis Rheum 1988;31:315-24

14 Petri M, Karlson EW, Cooper DS, Ladenson PW. Autoantibody tests in autoimmune thyroid disease: a case-control study. J Rheumatol $1991 ; 18: 1529-31$.

15 Imeryuz N, Yazici H, Kocak H, et al. Pericardial and pulmonary involvement in rheumatoid arthritis in Turkey. Clin Rheumatol 1994;13:239-43.

16 Wallace DJ, Linker-Israeli M. It's not the same old lupus or Sjögren's any more: one hundred new insights, approaches, and options since 1990. Curr Opin Rheumatol 1999;11:321-9.

17 Vlachoyiannopoulos PG, Karassa FB, Karakostas KX, Drosos AA Moutsopoulos HM. Systemic lupus erythematosus in Greece. Clinical features, evolution and outcome: a descriptive analysis of 292 patients. Lupus 1993;2:303-12.

18 Manthorpe R, Oxholm P, Prause JU, Schiödt M. The Copenhagen criteria for Siögren's syndrome. Scand J Rheumatol Suppl 1986;61:19-21. 